\title{
Disruptive selection and bet-hedging in planktonic Foraminifera: shell morphology as predictor of extinctions
}

\author{
Manuel F. G. Weinkauf ${ }^{1,2 *}$, Tobias Moller ${ }^{1}$, Mirjam C. Koch ${ }^{1}$ and Michal Kučera ${ }^{2}$ \\ Micropalaeontology, Department of Geosciences, Eberhard-Karls University, Tübingen, Germany \\ ${ }^{2}$ Center for Marine Environmental Sciences, Micropalaeontology-Palaeoceanography, University Bremen, Bremen, Germany
}

\section{Edited by:}

G. Lynn Wingard, U.S. Geological

Survey, USA

Reviewed by:

Pasquale Raia, Università di Napoli Federico II, Italy

Teresa Vegas-Vilarrúbia, University of Barcelona, Spain

*Correspondence:

Manuel F. G. Weinkauf, Center for Marine Environmental Sciences,

University Bremen, Leobener Str., Bremen 28359, Germany

e-mail:mweinkauf@marum.de
Extinction is a remarkably difficult phenomenon to study under natural conditions. This is because the outcome of stress exposure and associated fitness reduction is not known until the extinction occurs and it remains unclear whether there is any phenotypic reaction of the exposed population that can be used to predict its fate. Here we take advantage of the fossil record, where the ecological outcome of stress exposure is known. Specifically, we analyze shell morphology of planktonic Foraminifera in sediment samples from the Mediterranean, during an interval preceding local extinctions. In two species representing different plankton habitats, we observe shifts in trait state and decrease in variance in association with non-terminal stress, indicating stabilizing selection. At terminal stress levels, immediately before extinction, we observe increased growth asymmetry and trait variance, indicating disruptive selection and bet-hedging. The pre-extinction populations of both species show a combination of trait states and trait variance distinct from all populations exposed to non-terminal levels of stress. This finding indicates that the phenotypic history of a population may allow the detection of threshold levels of stress, likely to lead to extinction. It is thus an alternative to population dynamics in studying and monitoring natural population ecology.

Keywords: environmental stress, fluctuating asymmetry, growth symmetry, morphology, selection, planktonic Foraminifera, Mediterranean

\section{INTRODUCTION}

Being able to predict impending local extinctions in recent ecosystems could significantly enhance current techniques of biomonitoring. However, although recently large advances in the field of population dynamics channeling into extinction prediction has been made (Drake and Griffen, 2010) this application still suffers from the naturally large variability in population sizes (Ludwig, 1999). Indicators other than population dynamics may be more suitable as predictors for rising stress levels and local extinctions.

It has long been hypothesized that certain aspects of morphology, such as the continuity of growth regularity (fluctuating asymmetry, FA), are influenced by environmental stress (Furlow et al., 1997; Leung et al., 2000). Environmental stress is in this context defined as the degree of deviation of all environmental factors (biotic and abiotic) from the optimum requirements of a species. This hypothesis has been supported by studies where developmental instability was shown to be correlated with fitness (Lens et al., 2002; Hendrickx et al., 2003). In this context a decrease in variability is commonly attributed to stabilizing selection, often associated with reduced environmental variability (Van Valen, 1965), though it can also occur under fluctuating selection in an unstable, continuously changing environment (Pélabon et al., 2010). Increasing variability, on the other hand, is associated with disruptive selection (Bull, 1987), and can thus be the long-term result of bet-hedging of specimens that produce offspring with a higher inter-individual variability, thus increasing the mean fitness of the population (Slatkin, 1974;
Philippi and Seger, 1989; Grafen, 1999). Specifically, two different modes of bet-hedging can be distinguished (Einum and Fleming, 2004): (1) conservative bet-hedging, where the populations shows a directional developmental trend toward a state that would reduce fitness under optimal conditions but increases fitness under the prevailing parameters (Einum and Fleming, 1999), and (2) diversified bet-hedging where the population increases its variance so that the chances of at least some individuals to survive are maximized (Philippi and Seger, 1989).

Under natural conditions, it is difficult to assess at what stress levels stabilization yields to disruption. This is partly because it is difficult to identify suitable natural experiments, but most importantly because it is difficult to predict the outcome of stress exposure and thus stress severity on ecological time scales (Moritz and Agudo, 2013). The latter constraint does not apply to the fossil record, where the outcome of stress exposure can be directly observed. Unfortunately, in many cases the fossil record does not have the resolution and richness needed to assess morphological change acting on a spatially well constrained population. Additionally, when working with fossil material the fossilization potential of different biomaterials under varying depositional conditions can bias the preservation of the fossil record that can be used for such a study. In this respect, marine microplankton, such as planktonic Foraminifera, offer the best model system. Foraminifera possess intricate geometrical shells consisting of sequentially accreted chambers, thus reflecting aspects of individual growth, despite their unicellular grade of organization. The 
calcite shells of planktonic Foraminifera are preserved in large quantities in marine sediments deposited above the carbonate compensation depth, leaving a highly representative record of population changes through time (e.g., Kučera, 2007).

Studies of recent planktonic Foraminifera have shown abundant evidence for changes in shell traits along environmental gradients (Malmgren and Kennett, 1976), suggesting that individual growth characteristics in these organisms react to changes in environmental parameters. The geometry of Foraminifera shells is given by cytoskeleton assembly during the calcification of each new chamber (Bé et al., 1979). Under extreme stress, e.g., poisoning by heavy metals, the ability of Foraminifera to constrain the shape of their shells is limited, leading to aberrant morphologies (e.g., Caron et al., 1987; Alve, 1991). These effects are most likely associated with direct cytotoxicity, interfering with cytoskeleton assembly. Although no experimental studies exist that assess the influence of natural levels of stress on the geometry of Foraminifera shells, it is likely that their growth regularity may be affected. In multicellular organisms, it is known that exposure to environmental stress can decrease the ability of chaperones to facilitate the conformation of structurally relevant enzymes (Debat et al., 2006). This effect can lead to morphological deviations during the growth of an organism, and can thus serve as a proxy for the occurrence of such stress during the lifetime of the organism (Hendrickx et al., 2003; Beasley et al., 2013).

In this study we present a morphometric analysis of two species of planktonic Foraminifera during the onset of the deposition of Sapropel S5 in the Eastern Mediterranean Sea (Figure 1) (Cane et al., 2002). The oxygenation of the deeper water column in this area is facilitated by thermal sinking of saline $(39 \%$ ) surface waters (Rohling et al., 2009). About 124 kyrs ago, a

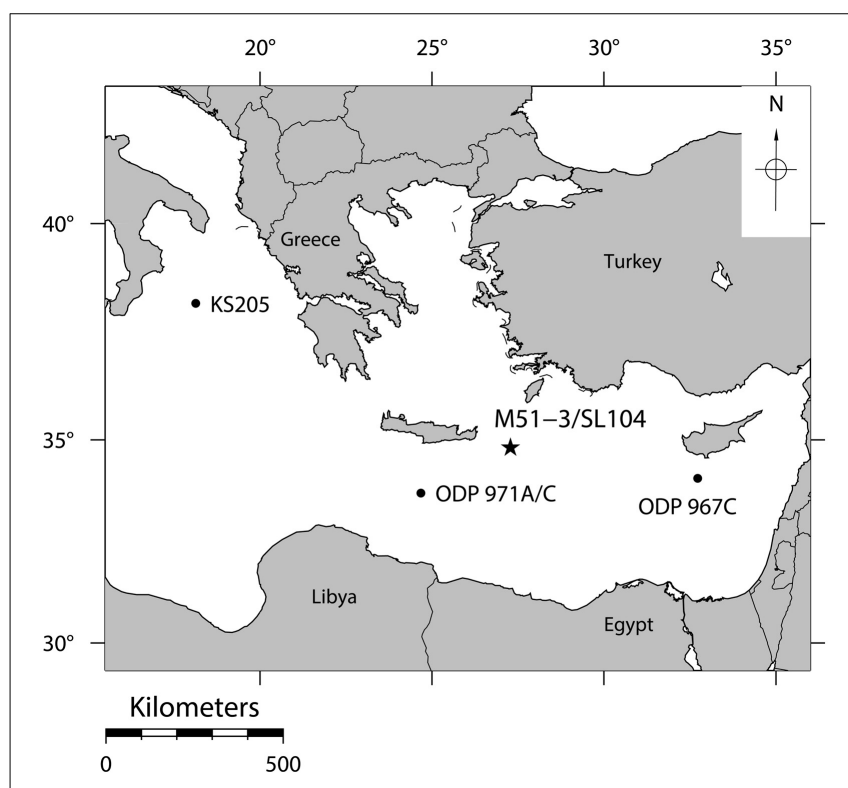

FIGURE 1 | The position of core M51-3/SL104 in the Pliny Trench about $\mathbf{1 0 0} \mathbf{~ k m}$ east-south-east of Crete where the reaction of planktonic Foraminifera to stress has been studied. Positions of other cores, where the same local extinctions of the species investigated here have been observed (Cane et al., 2002), are indicated by black dots. strengthened monsoon over Africa significantly reduced the surface water salinities in the Eastern Mediterranean due to a distinct rise in freshwater inflow via the Nile (Williams et al., 1978). This process left a distinct signature in the form of significantly lighter stable oxygen isotope values of the upper water column. The excess freshwater influx led to a reduction of surface water salinity from ca 39 psu to ca 35 psu (Van Der Meer et al., 2007), preventing deep water formation. The resulting stagnation of the vertical circulation led to deep water anoxia and the deposition of organic rich sapropel layers (Rossignol-Strick et al., 1982; Rohling, 1994). Because of common forcing by increasing summer insolation, contemporaneously to the onset of the sapropel deposition, local sea surface temperature (SST) rose by approximately $3^{\circ} \mathrm{C}$ (Marino et al., 2007). In response to these events, local extinctions of several species of planktonic Foraminifera occurred throughout the entire Eastern Mediterranean (Figure 1) (Cane et al., 2002). It must be made clear that those local extinctions do not belong to any kind of absolute extinction as described by Delord (2007), but are rather regional disappearances of the species within the Eastern Mediterranean. Many if not all of those species reinvaded the Eastern Mediterranean at a later point when environmental conditions switched back to a previous state, and all those species still exist until the present day at least in other regions of the world. Since those local extinctions appeared on a regional scale, and are therefore not merely the result of migration patterns, however, marine sediments with fossils of Foraminifera from this period provide a direct record of a natural stress experiment that took place over ecological time scales, which could not be simulated during laboratory experiments. This advantage comes at the price, however, that the natural experiment can only be observed at limited time resolution and that the sampling is affected by temporal averaging. In addition, our ability to identify the stressors responsible for the reaction of the ecosystem is limited.

In an earlier study Weinkauf et al. (2013) have shown, that in the same environmental setting, the terminal stress level (i.e., a severity of stress that leads to local disappearance of the species) did not influence the ability of the Foraminifera to calcify their shells on a cellular level, but the events associated with the onset of the sapropel deposition had an effect on the calcification intensity of the Foraminifera. Since shell calcification in planktonic Foraminifera is strictly controlled by the living cell (e.g., Bé et al., 1979; Spero et al., 1991) this is likely to reflect the influence of a physiological process associated with the environmental change, rather than just a passive environmental effect. It is thus reasonable to assume that the shell morphology might have been influenced as well. Our hypothesis is, therefore, that morphological changes associated with different levels of stress occurring around the onset of Sapropel S5 should be detectable in the fossil record of planktonic Foraminifera. If this is the case, the state of the populations recorded shortly prior to extinction should reflect the phenotypic response of the exposed population to a terminal level of stress, when compared to the unstressed replicates before.

\section{MATERIALS AND METHODS CHOICE OF SAMPLING INTERVAL AND SPECIES}

The sampling interval and species (Orbulina universa and Globorotalia scitula, Figure 2) for this study were chosen to cover a 


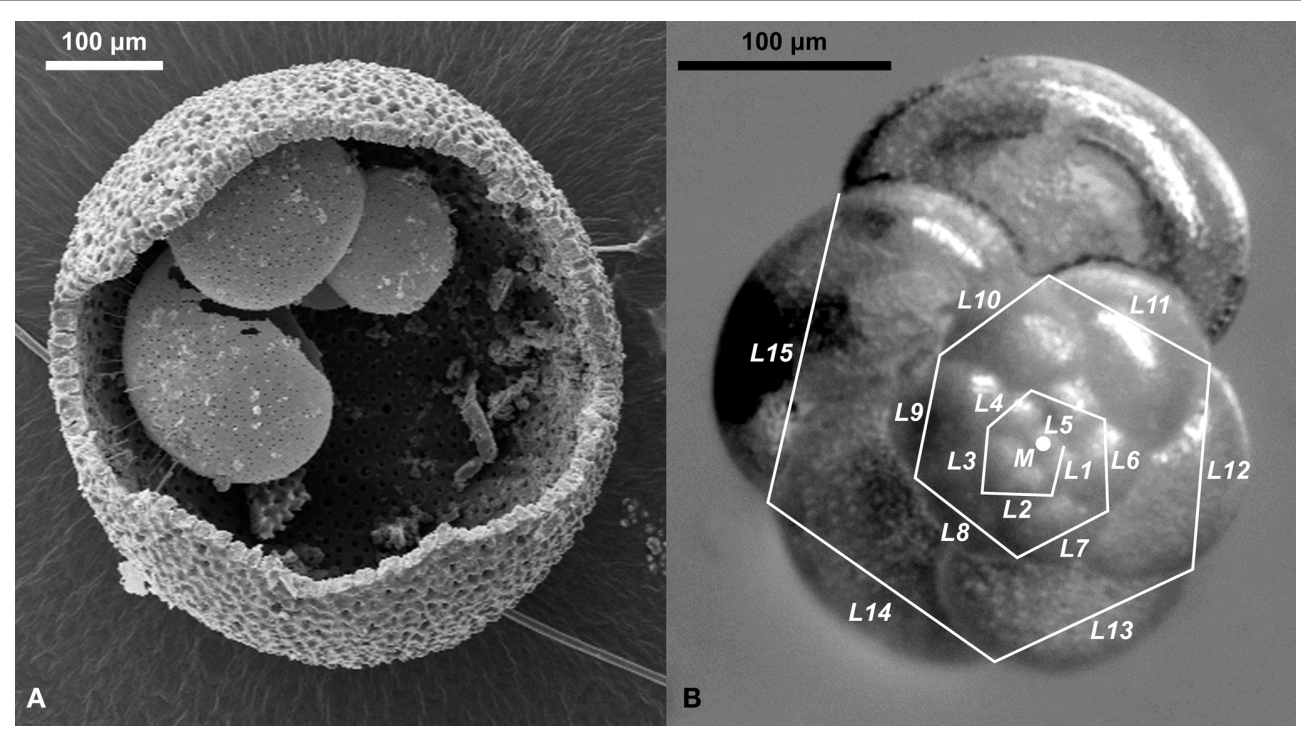

FIGURE 2 | Depiction of species used in this study. (A) Scanning electron micrograph of a cracked open shell of Orbulina universa, showing the delicate trochospiral juvenile shell preserved within the spherical terminal chamber. (B) Measurement of the incremental growth in Globorotalia scitula. Straight lines were drawn between consecutive chamber sutures and their length was measured $(L 1-L 15)$. The relative change of length between individual line segments was used to calculate the incremental growth IG (mean relative length change between consecutive line segments) and an incremental growth variance IGV (standard deviation of $(G)$ per specimen. The coordinates of the sutures and the spiral center $(M)$ were used to describe the deviation of growth from the logarithmic spiral. wide ecological spectrum and to replicate the observations on the impact of terminal stress leading to local extinction. By including those species in our analysis over an interval that covers several centuries before and after the onset of sapropel deposition we can assess the impact of the presumed salinity shift in the upper water column, as well as the impact of vertical stagnation on the lower water column.

Orbulina universa is a shallow-dwelling, symbiont-bearing species with dwelling depths of 20-100 m (Pujol and Vergnaud Grazzini, 1995; Rohling et al., 2004). The species survived the onset of Sapropel S5, but shows two local extinctions within the sapropel (Figure 3) (Cane et al., 2002). Orbulina universa is known to be associated with cryptic speciation encompassing at least three distinct genetic types (De Vargas et al., 1999). Although only one genetic type was found in the Mediterranean so far (De Vargas et al., 1999), we cannot exclude the possibility, that cryptic speciation influenced the results obtained in our analysis. If this would be relevant for our analysis, however, we should observe a bi- or multimodal distribution of measurement values, with changing mode amplitudes indicating that any observed change in the mean value of morphometric data is the result of changing dominances of sub-populations within the community. A unimodal distribution, on the other hand, indicates a (at least morphologically) homogeneous community that shows a consolidated reaction regardless of their potential cryptic diversity. Consequently, we used Hartigan's dip test (Hartigan and Hartigan, 1985) to test the morphometric data for unimodality.

Globorotalia scitula is a deeper dwelling species without symbionts, which shows a local extinction contemporaneous with sapropel onset (Figure 3). It was found to be most abundant between 200 and $500 \mathrm{~m}$ water depth in the Azores region (Schiebel et al., 2002), which is in good agreement with its reconstructed depth habitat during the deposition of Sapropel S5 (Rohling et al., 2004). The genetic diversity of G. scitula has not yet been assessed in detail.

The sampling interval covers the onset of Mediterranean Sapropel S5 at around $126.4 \mathrm{ka}$, which is visible by both the sediment becoming considerably darker in color and a drop of the $\delta^{18} \mathrm{O}$ values of shells of Globigerinoides ruber (white) from $0.5 \%$ to $-1.4 \%$. Specimens of $G$. scitula became locally extinct with the onset of the sapropel, and specimens of that species therefore only cover pre-sapropel conditions in our study, covering a timespan of nearly 1800 years. Orbulina universa survived the sapropel onset to become locally extinct later, and thus covers the same time period as G. scitula before sapropel onset and an additional 2000 years within the sapropel.

\section{SAMPLE PROCESSING}

The samples were taken from a portion of gravity core M51-3/SL104, taken in the Pliny Trench east-south-east of Crete in the Eastern Mediterranean (Figure 1) (Hemleben et al., 2003), covering the onset of Sapropel S5 (Moller et al., 2012). The sediment was deposited ca. 126-121 kyrs ago, and an age model was fitted using a combination of event-stratigraphy (Cane et al., 2002) and layer counting in the laminated part of the sapropel (Moller, 2012). The sampling was performed with a spatial resolution of $3 \mathrm{~mm}$, which corresponds to a temporal resolution of 60-70 yrs in the majority of the section, and about 11 yrs in the topmost $6 \mathrm{~cm}$ of the studied interval, covering only the second local extinction of $O$. universa. The samples were washed using tap water and dry sieved, only the fraction $>150 \mu \mathrm{m}$ was used for subsequent analyses. 


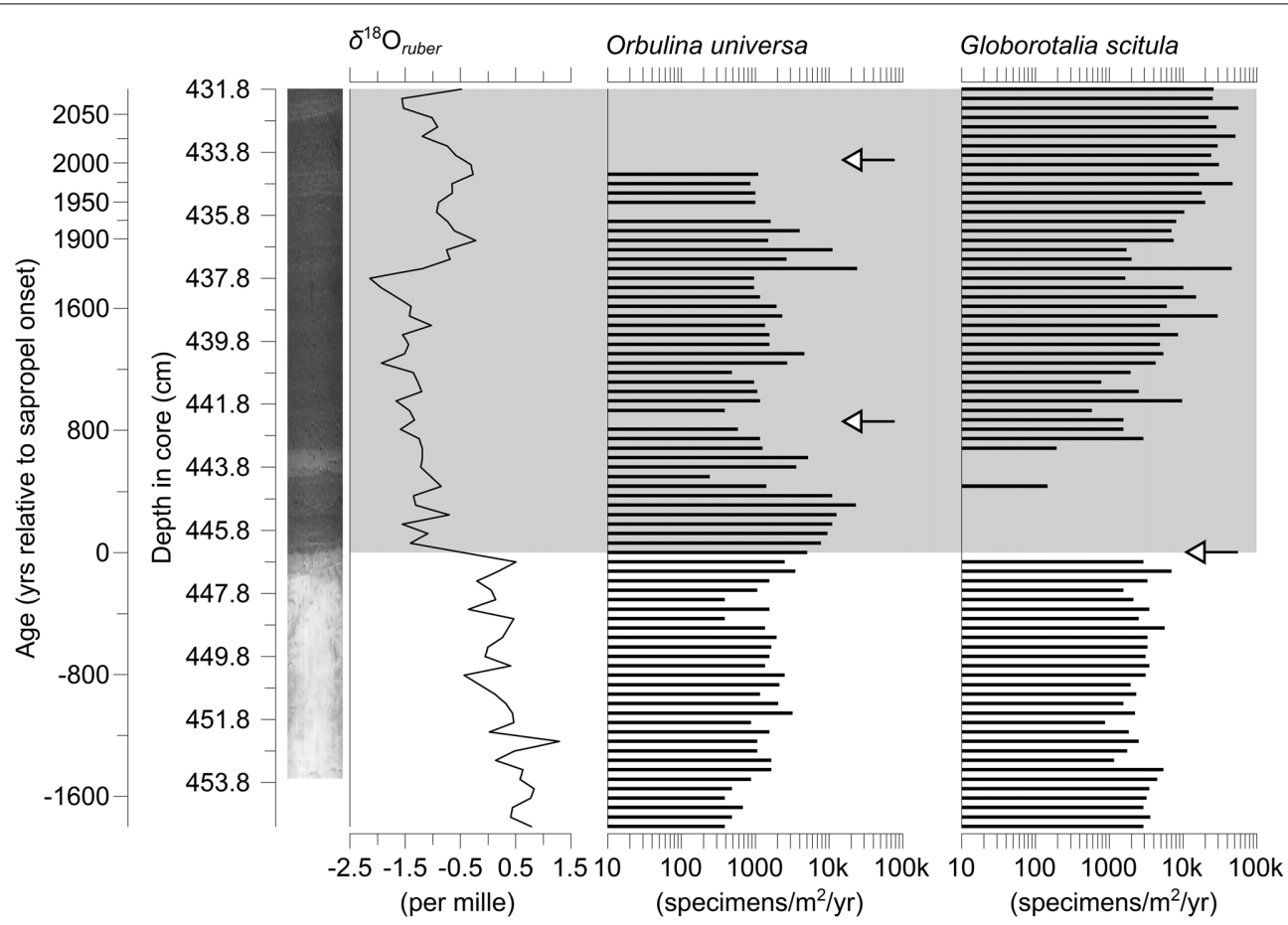

FIGURE 3 | Accumulation rates of shells of the two species of planktonic Foraminifera in core M51-3/SL104 investigated in this study. The $\delta^{18} \mathrm{O}$ values of shells of Globigerinoides ruber (white) from the same core serve as a geochemical marker for freshwater injection marking the onset of the sapropel. Local extinctions occurring in the entire Eastern Mediterranean (Cane et al., 2002) are marked with arrows. The gray-shaded area indicates the extent of Sapropel S5, a core-photograph is provided for visualization.
Foraminifera were picked from representative aliquots of the washed residue, split with a binary microsplitter if necessary. Orbulina universa was picked from $455.5-434.8 \mathrm{~cm}(70$ samples) and yielded 2025 specimens. Of G. scitula 1290 specimens were sampled, ranging from $455.5-447.1 \mathrm{~cm}(29$ samples). The abundance of each species in the analyzed aliquots was determined on the basis of faunal count data assessed from $12.5-100 \%$ of the sample volume. Absolute abundances were converted to accumulation rates per square meter per year, using the inferred age model and the crosssectional area of the samples, assuming constant sample thickness.

\section{MORPHOMETRIC DATA ACQUISITION}

All specimens were oriented in standard taxonomic view, mounted on glass slides using double sided adhesive tape, and photographed under constant magnification with a Leica Z16 stereomicroscope and the Image-Pro ${ }^{\circledR}$ Plus software. All specimens were photographed using transmitted light, specimens of G. scitula from selected samples were additionally photographed under reflected light to enable analysis of growth patterns.

Orbulina universa is characterized by a trochospiral juvenile shell, that in the terminal life stage is completely overgrown by a spherical terminal chamber, so that adult specimens (which were used in our study exclusively) normally resemble spheres (Figure 2). Abnormal morphotypes are known to exist and believed to occur under stress conditions (Caron et al., 1987).
Those include "Orbulina suturalis," in which part of the juvenile shell is not covered by the terminal chamber, and "Biorbulina bilobata," in which the adult shell is composed of two joint hemispheres (Figure 4). In O. universa the mean diameter and roundness (expressed as ratio between longest and shortest axis) of the shell, and the incidence of the abnormal morphotypes were determined.

Globorotalia scitula grows a flat, trochospiral shell (Figure 2). In this species the cross-sectional shell area, incidence of antisymmetry (left-coiling), and Kummerforms (specimens in which the last chamber is smaller than the penultimate chamber, Figure 4) were determined.

Using reflected light images, the incremental growth of G. scitula in selected samples was analyzed by drawing $n$ straight line segments of length $l_{i}$ between consecutive chamber sutures along the shell outline (Figure 2). The relative length relationship between consecutive lines per specimen was then used to calculate the incremental growth $I G$ (mean relative growth, Equation 1) and incremental growth variance $I G V$ (intra-individual standard deviation of relative growth, Equation 2) for each specimen. Only specimens in which at least five consecutive line segments could be measured were used for the analysis. The spiral formed by the $x-y$-coordinates of sutures (normalized for a standard spiraldiameter of one) was used to estimate the deviation of the shell from the logarithmic spiral. The $R^{2}$ value of a ranged major axis regression line (Legendre and Legendre, 2012) through the logarithmically plotted points $\left(\log -R^{2}\right)$ provided an objective measure of that deviation. 


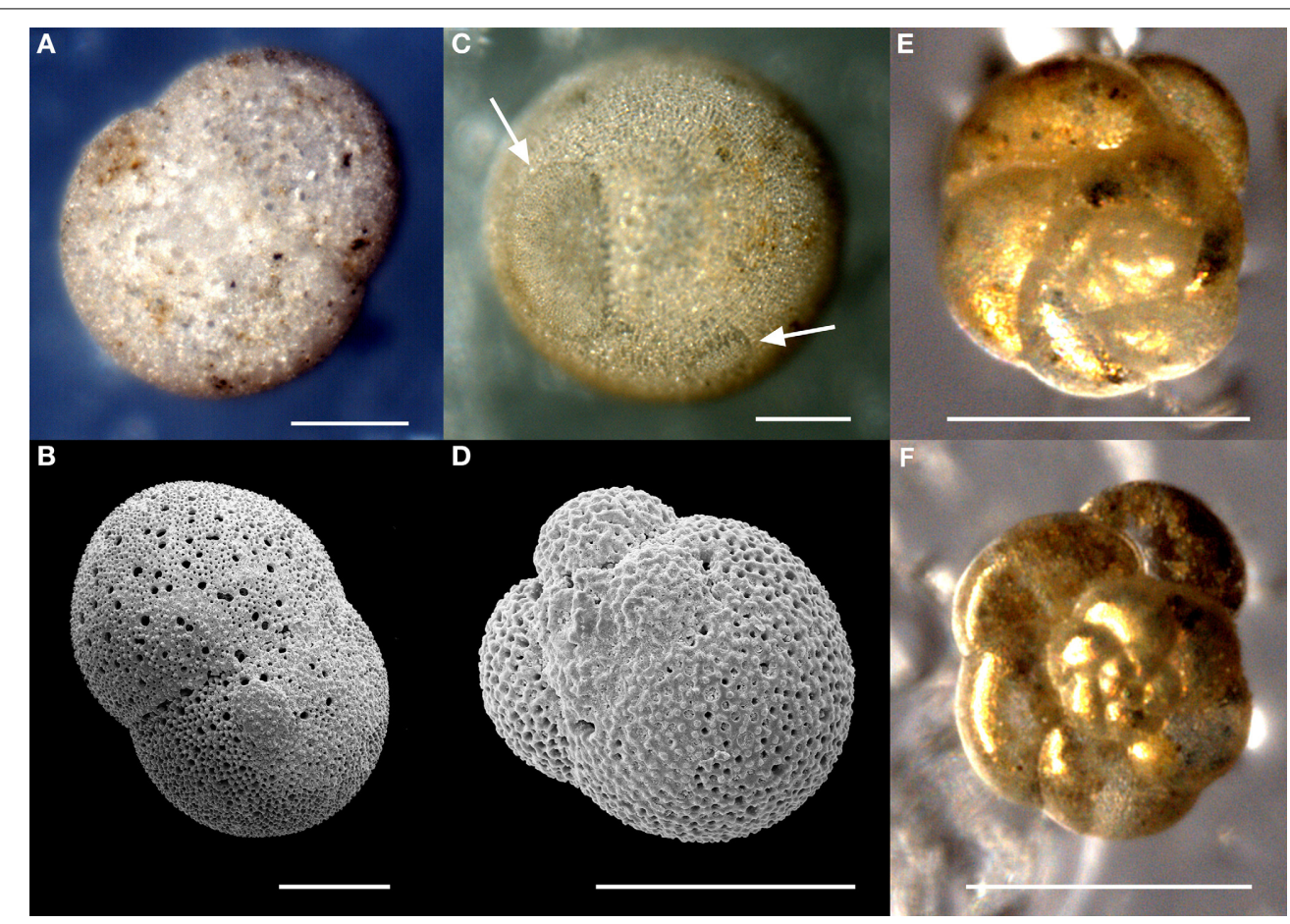

FIGURE 4 | Depiction of abnormal morphotypes. (A,B) Specimens of "Biorbulina bilobata," an abnormal morphotype of Orbulina universa where the adult shell consists of two hemispheres that are joined in the middle, in light microscopic (A) and scanning electron microscopic (B) view.

(C,D) Specimens of "Orbulina suturalis," an abnormal morphotype of Orbulina universa where the juvenile trochospiral shell (compare Figure 2) is not completely enclosed by the adult spherical shell, in light microscopic
(C) and scanning electron microscopic (D) view. The protruding juvenile spiral has been marked by arrows in the light microscopy image. (E,F) Light microscopy images of Kummerforms of Globorotalia scitula, where the last chamber is smaller than the penultimate chamber. While the specimen in (F) shows a regular growth pattern (low IGV) the specimen in (E) shows an increased IGV visible by the large variation in the size of individual chambers. Scale bars are $200 \mu \mathrm{m}$ in length.

$$
\begin{aligned}
I G & =\frac{\sum_{i=2}^{n} l_{i} / l_{i-1}}{n-1} \\
I G V & =\sqrt{\sum_{i=1}^{n} \frac{\left(l_{i} / l_{i-1}-I G\right)^{2}}{n-2}}
\end{aligned}
$$

The chosen parameters allow us to assess the influence of environmental stress on the morphology of those two foraminifer species on several levels: (a) body size appears to reflect environmental stress in planktonic Foraminifera, because it is known to decrease away from the thermal optimum of each species (Schmidt et al., 2004). (b) The incidence of abnormal morphotypes (including antisymmetry) is likely to increase under stress indicating disruption of morphogenesis. (c) The roundness in O. universa and $I G, I G V$, and $\log -R^{2}$ in $G$. scitula are an imprint of the FA in those organisms, which is a proxy for environmental stress in multicellular organisms (Leung et al., 2000).

\section{DATA ANALYSIS}

Statistical analyses of the results were performed in $\mathrm{R} \mathrm{v}$. 3.0.1 ( $\mathrm{R}$ Development Core Team, 2013). Confidence intervals of morphological parameters were calculated by bootstrapping using the package "boot" v. 1.3-9 (Davison and Hinkley, 1997), with bootstrapping method choice based on skewness evaluation following Dixon (2002). Skewness (SK) was calculated according to recommendations in Tabor (2010) (equation I, table 1), its standard deviation $S D K$ for $n$ data values was approximated as $S D K=2 \times(6 / n)^{\frac{1}{2}}$ (Tabachnick and Fidell, 1996). The skewness of the data was considered significant when $S K>S K D$. When the skewness was significant, the basic bootstrap, otherwise the accelerated bootstrap, was used.

For all relative abundances, 95\% confidence intervals for multinomial proportions were calculated (Heslop et al., 2011). The normality of data distribution was tested using a ShapiroWilk test (Shapiro and Wilk, 1965) wherever necessary to decide between the applicability of parametric or non-parametric tests. Comparisons between the morphological characteristics between two groups (i.e., specimens before and after sapropel onset) were performed by a Mann-Whitney $U$ test (Mann and Whitney, 1947).

Morphological growth parameters in G. scitula where tested for deviations per sample using Grubb's test for outliers (Grubbs, 1969). To test for the development of increasing (disruptive selection) or decreasing (stabilizing selection) morphological plasticity as result of the environmental stress, we calculated the standard deviation including its 95\% confidence interval (Sheskin, 2011) for each of the morphological parameters in each sampling level. 


\section{RESULTS}

In both species investigated local disappearances could be observed as expected. Orbulina universa shows two such disappearances, both within the sapropel, while G. scitula disappeared immediately before sapropel onset (Figure 3). In both cases there were no signs of dissolution visible on the foraminiferal shells, with even specimens of fragile, thin-walled species being in a pristine state with transparent shell walls. We further note the occurrence of pteropods throughout the whole sampling interval, which are very susceptible against dissolution due to the aragonitic nature of their shells, and have therefore no reason to assume that the disappearances we observe are the result of diagenetic processes instead of local extinctions.

In O. universa, mean shell size showed no obvious difference between pre- and post-sapropel populations $(p=0.459)$ or at local extinctions (Figure 5), but the distribution of individual
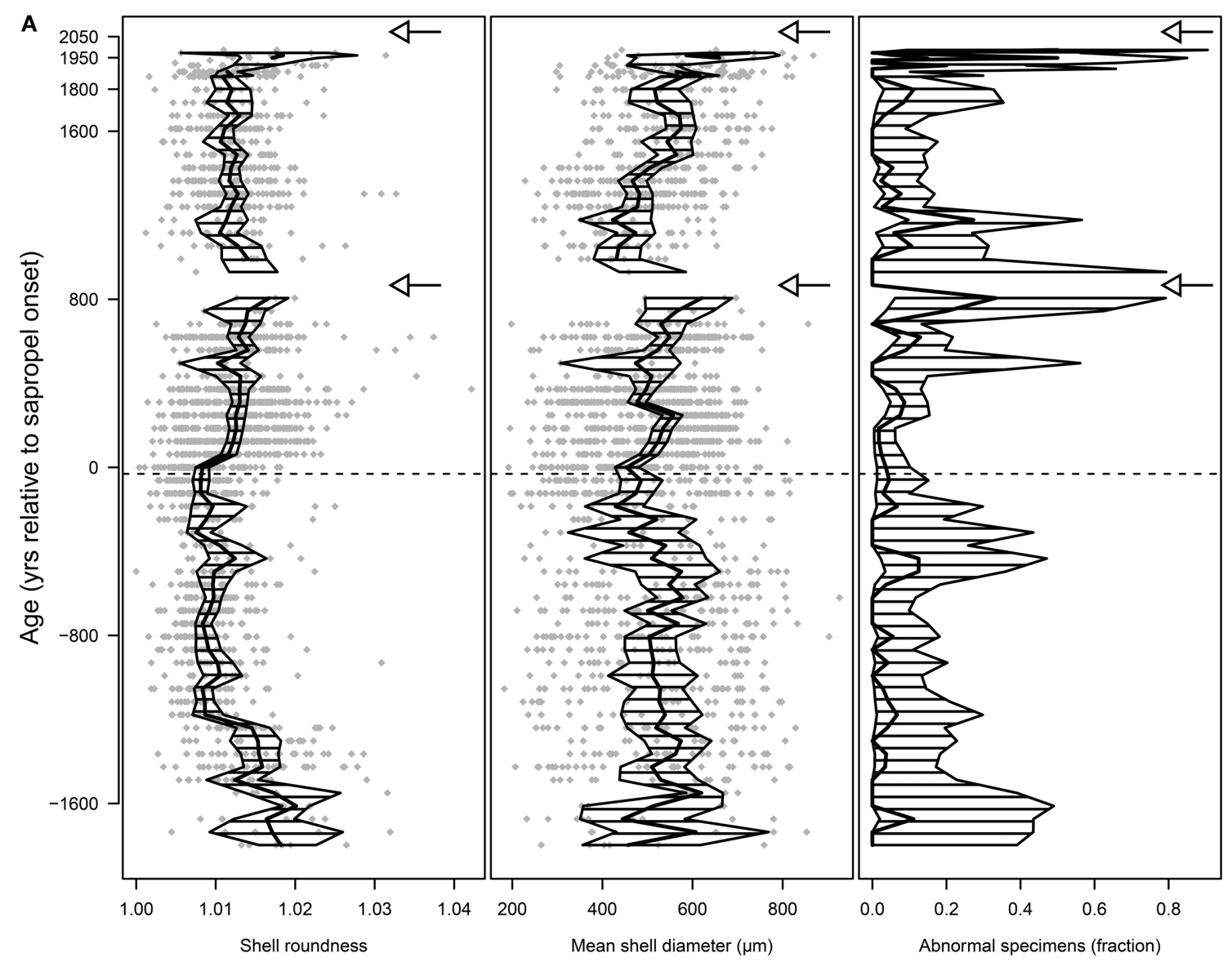

B

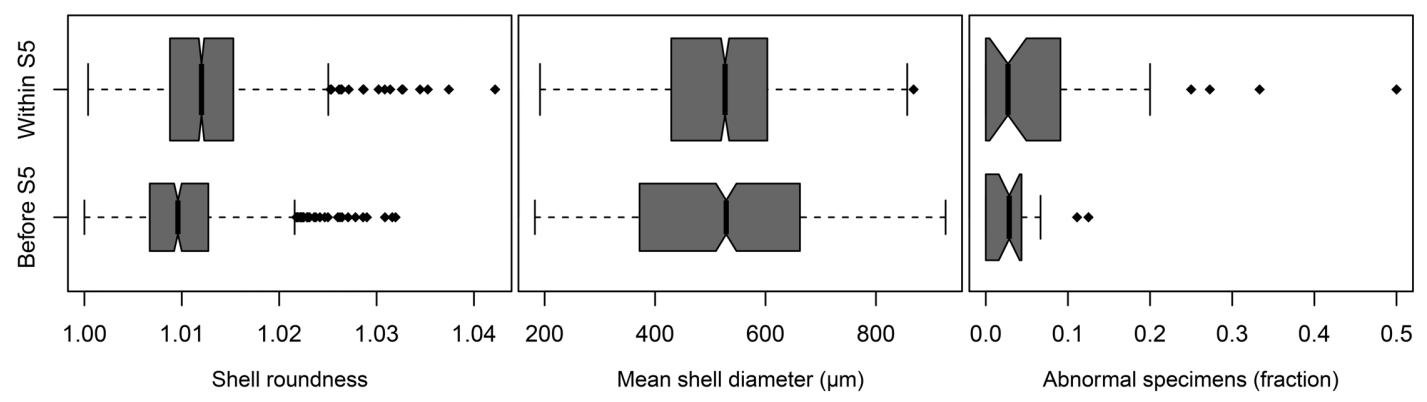

FIGURE 5 | Morphological analyses of shells of Orbulina universa from core M51-3/SL104. Shell roundness is the ratio between long and short axis of the shell, a value of 1.0 representing a perfect sphere. The incidence of abnormal morphotypes combines counts of specimens of the two ecophenotypes "Biorbulina bilobata" and "Orbulina suturalis," the arrows mark the local extinctions of the species. (A) Stratigraphic plots depicting the raw values for shell roundness and diameter (gray diamonds), the arithmetic mean values (thick black line), and the $95 \%$ confidence intervals of the mean (hatched area). The horizontal dashed line marks the onset of Sapropel S5. Note the increasing abundance of abnormal morphotypes before both local extinctions. (B) Distribution of values before and within the sapropel. The boxes show the median (thick black line), interquartile range (box), and $1.5 \times$ interquartile range (whiskers); black diamonds mark outliers. Box widths are proportional to the number of within-groups observations. Note the difference in mean shell roundness and average incidence of abnormal morphotypes, but not in mean shell diameter within the sapropel. 
values indicates a significant decrease in variance $(p<0.001)$ with the onset of the sapropel (Figure 5B, Supplementary Figure $3 \mathrm{~A})$. The mean roundness of the terminal chamber changes with sapropel onset (Figure 5, Supplementary Figure 3A). The difference between pre- and post-sapropel conditions is significant at $p<0.001$ but it is not associated with a change in variance $(p=0.501)$.

Within the sapropel, the abundance of abnormal morphotypes of $O$. universa is generally increased in comparison to pre-sapropel conditions ( $p=0.015$, two-proportions $z$-test). Furthermore, the incidence of abnormal morphotypes appears to be highest in samples immediately preceding both local extinctions. Although the associated confidence intervals of the relative abundances of " $O$. suturalis" and "B. bilobata" are large
(Figure 5A), indicating the possibility of a spurious effect, a randomization test, in which randomly selected three-sample groups were compared to each of the three-sample groups before both local extinctions, indicate a significance of the increased incidence of abnormal morphotypes for the second local extinction $(p=0.011)$, but not for the first one $(p=0.277)$.

Globorotalia scitula showed no reaction in shell size toward its local extinction. The species also showed no significant reaction in the incidence of left-coiled specimens $(p=0.138$ for the last two samples before local extinction) or Kummerforms at that time (Figure 6A).

Conversely, the values of $I G$ and $I G V$ were increasing when the species approached its local extinction (Figure 6B). Hypothetically it could be assumed, that from some point when
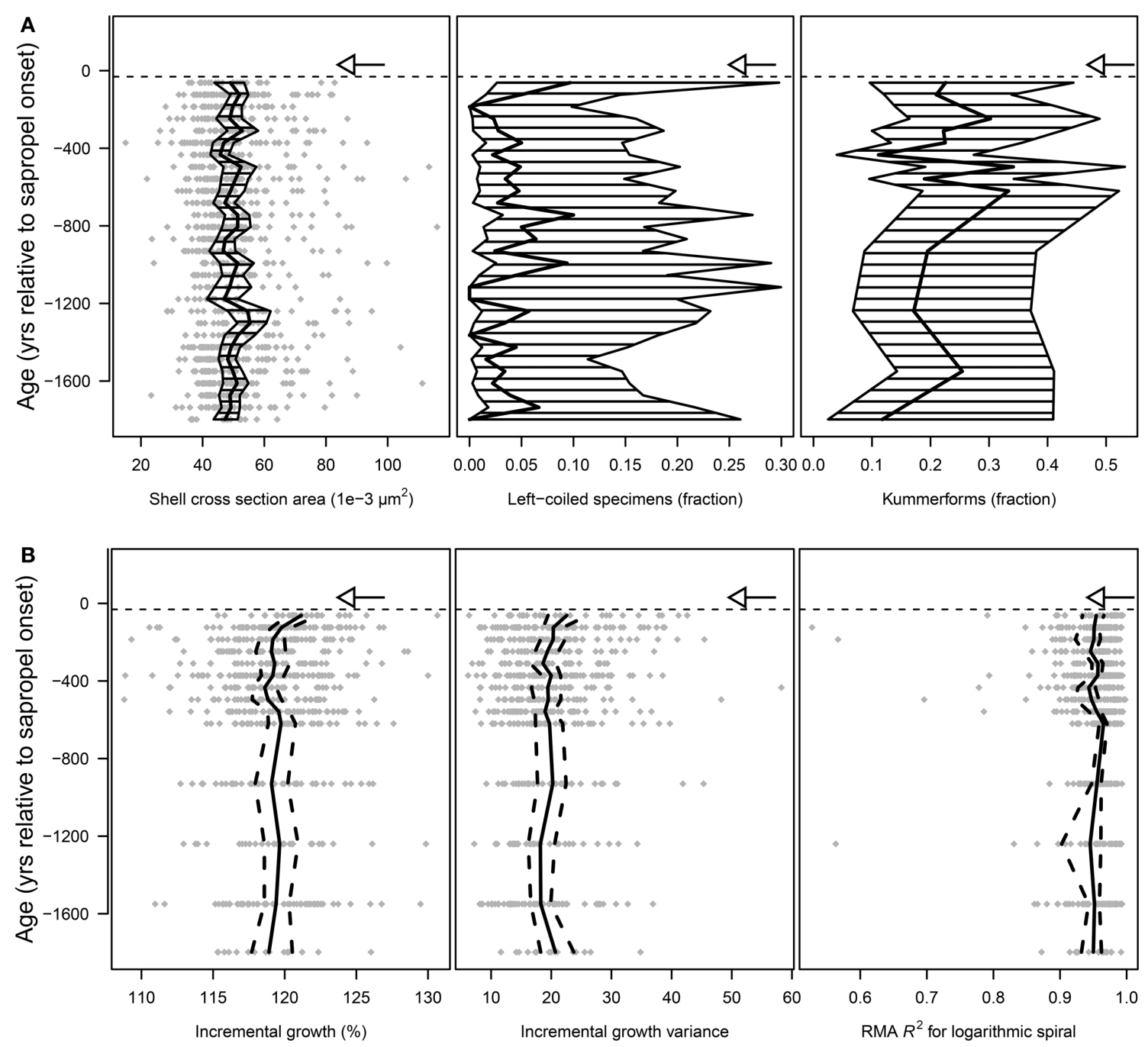

FIGURE 6 | Morphological analyses of shells of Globorotalia scitula from core M51-3/SL104. Kummerforms are specimens in which the last chamber is smaller than the penultimate chamber. The horizontal dashed lines mark the onset Sapropel S5, the arrows mark the local extinction of the species (A) Arithmetic mean values (thick black line) and 95\% confidence intervals of the mean (hatched area), and in the case of shell size the raw values as gray diamonds. (B) Raw values (gray diamonds) and mean (solid black line) with 95\% confidence interval (dashed black lines) of the incremental growth (/G) and its standard deviation (IGV) and the deviation of growth from the logarithmic spiral. Both $I G$ and IGV rise significantly when $G$. scitula approaches its local extinction, whereas the consistency of the logarithmic growth remains the same (compare Supplementary Table 1). 
the species approaches its local extinction, a deviation in the growth pattern could be observable, when compared to the background value that prevailed before. To that end, we applied Grubb's test for outliers to check if such a pattern can be recognized in our samples. One-tailed $p$-values for this analysis show that a significant change in $I G(p=0.002)$ and $I G V(p=0.024)$ only occurs in the very last sample where the species was found, i.e., about 60 years prior to its local extinction (Supplementary Table 1). Disregarding those outliers the rest of the data is normally distributed $\left(p_{I G}=0.781, p_{I G V}=0.518\right)$, so that the assumptions to apply Grubb's test are not violated. Furthermore, while the whole community shows a consistent increase in $I G$, the population-wide variance of $I G V$ is also increasing when the species approaches local extinction (Figure 6B, Supplementary Figure 3B). The growth symmetry, measured by the deviation of the growth spiral from an ideal logarithmic spiral, shows in contrast no reaction when the species approached its local extinction ( $p=0.487$, Figure 6B, Supplementary Table 1 , data are normally distributed at $\left.p_{R^{2}}=0.678\right)$.

\section{DISCUSSION}

\section{RELIABILITY AND NATURE OF OBSERVED MORPHOLOGICAL PATTERNS}

Although not all of the observed morphological variance within Foraminifera can be explained by genetic diversity (André et al., 2013; Mary and Knappertsbusch, 2013) a high genetic variability within Foraminifera was revealed (De Vargas et al., 1999; Aurahs et al., 2011), so that changing morphologies could theoretically be the result of changing dominances of different genotypes. Although until now only one genetic type of $O$. universa is known to occur in the Mediterranean (De Vargas et al., 1999), the trait shifts observed in that species could be the result of a non-constant mixing of different genetic types with different morphologies. However, since we did not find any coherent signal of non-unimodality in the size and roundness measurements (Supplementary Table 2, Supplementary Figures 1, 2), we assume that the analyzed specimens derive from one homogenous community, within which the traits changed with sapropel onset. The results we obtained during our analyses are thus robust with regard to potential genotypic variation and speciation.

We interpret the reduced shell roundness with constant interindividual variance in O. universa (Figures 5B, 7A) as a signal of a permanently increased FA in its population during sapropel times. Conversely, the constant shell size with significantly reduced inter-individual variance during sapropel times (Figures 5B, 7A) indicates stabilizing selection on that trait. The increased incidence of abnormal morphotypes immediately before local extinction (Figures 5, 7A) is distinct from both patterns and is more likely a reflection of excessive conservative bet-hedging.

The increase in mean values of incremental growth and its variance shortly before the local extinction of $G$. scitula (Figures 6B, 7B) signifies an increase in FA. While the inter-individual variance of $I G$ was unaffected by the observed local extinction, the inter-individual variance of $I G V$ was drastically increased in the last sample before local extinction (Figures 6B, 7B, Supplementary Figure 3B), indicating diversified bet-hedging. These observations imply that specimens of
G. scitula began to grow faster (i.e., adding larger chambers) shortly before local extinction whilst at the same time the intraindividual continuity of chamber size was significantly decreased. Moreover, while the increase in $I G$ affected the whole community alike, the $I G V$ showed a high inter-individual variance at the same time, implying that the observed reaction affected only part of the investigated community.

\section{STABILIZING AND DISRUPTIVE SELECTION AND BET-HEDGING IN PLANKTONIC FORAMINIFERA \\ Stabilizing selection on shell size}

Haenel (1987) interpreted the size of shells of O. universa as an indicator of water salinity, arguing that the larger size counteracts buoyancy when the water becomes less dense due to a reduction in salinity. An alternative hypothesis correlates the size of the terminal chamber in O. universa with food availability (Spero, 1988), arguing that the energy needed to generate a larger terminal chamber can only be compensated by larger energy reserves within the cell. Under those assumptions, larger shells should have been observed within the sapropel, since sea water salinity was reduced (Van Der Meer et al., 2007) and the primary productivity was higher (Struck et al., 2001) during sapropel conditions.

Rather than such predicted changes in the mean shell size of the population, we observe a significant decrease in shell-size variability in $O$. universa after the onset of the sapropel deposition. We hypothesize, that the higher variability in shell size in O. universa before sapropel onset reflects disruptive selection, where a higher variability of the community is necessitated to sustain under sub-optimal conditions. The lack of a bimodal size-distribution at that time is here interpreted as a sign of a moderate disruption, and is also what one would expect with disruptive selection under random mating models that can arguably be assumed for Foraminifera (compare Doebeli, 1996). During sapropel conditions, on the other hand, the environmental niche of the species was narrowed, with more open-marine conditions (normal marine salinity) and high nutrition values of the sea water (Struck et al., 2001) that could better sustain a population with lower phenotypic plasticity due to higher resource availability for an abundant mean phenotype (Rueffler et al., 2006).

The local extinctions, however, did not leave any discernible imprint in the size distribution of either of the two species, rendering this trait useless for extinction prediction. Furthermore, this is evidence against the hypothesis, that larger shell sizes are correlated with favorable environmental conditions (Ortiz et al., 1995; Schmidt et al., 2004), because then we would expect to find smaller specimens at times of enhanced stress levels, such as prior to local extinctions.

\section{Fluctuating asymmetry as a proxy for stress}

The roundness of the terminal chamber in O. universa shows a significant reduction after sapropel onset, contemporaneously with a reduction in shell calcification which was hypothesized to reflect the influence of the reduced surface water salinity and resulting change in the $\mathrm{CO}_{3}^{2-}$ equilibrium of the sea water after the onset of the sapropel (Weinkauf et al., 2013). 

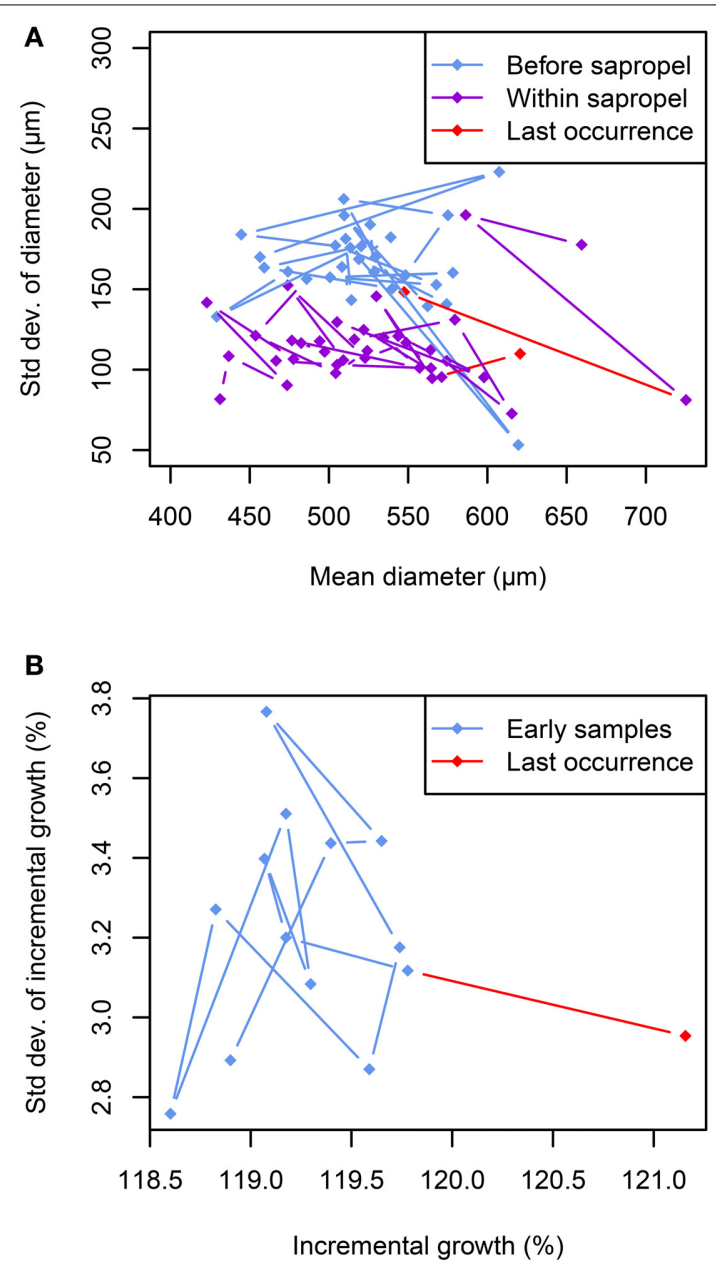

FIGURE 7 | Morphological trends in foraminiferal shells during extinction periods. (A) Evolution of size and roundness and incidence of abnormal morphotypes in Orbulina universa across the onset of the Sapropel S5 deposition in core M51-3/SL104. The shell diameter shows no change with sapropel onset, but size variability is reduced within the sapropel. In contrast, shells within the sapropel are on average significantly less round than for the majority of the time before sapropel onset. The incidence of abnormal
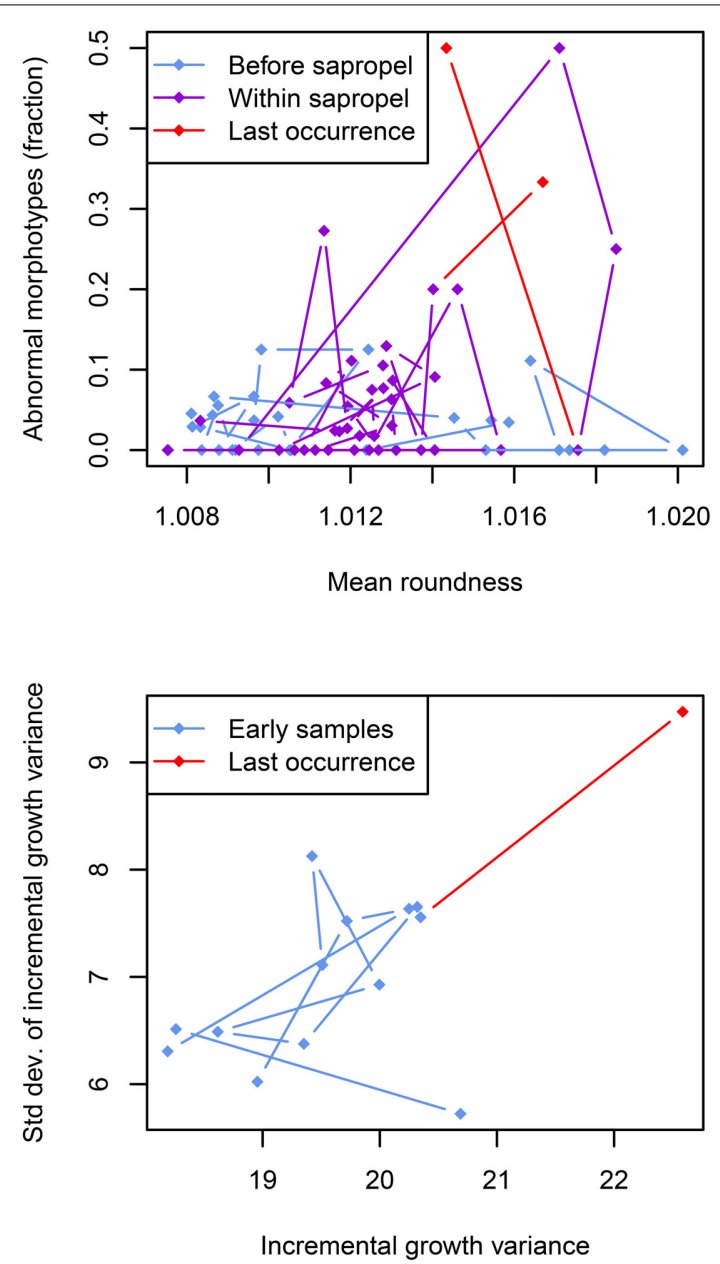

morphotypes is generally higher within the sapropel than before, with peak abundances before local extinctions. (B) In Globorotalia scitula a change in the spiral growth pattern can be observed immediately prior to local extinction. While the mean value of incremental growth increases (indicating the building of larger chambers), its variance remains the same on the population level. However, the incremental growth variance within an individual becomes both larger and more variable on the population level.
Considering the fact that mean shell roundness is constantly low over long time intervals, but without exhibiting any deviation when the species approaches local extinction (Figure 5A), the reduction in roundness seems to have been induced by environmental parameters which are not themselves unfavorable for that species. It has been suggested that the shell roundness of O. universa decreases under conditions of high nutrient availability (Robbins, 1988; Spero, 1988), which can be assumed during sapropel deposition (Struck et al., 2001). The same factors were also argued to be responsible for higher incidences of abnormal morphotypes in O. universa (Robbins, 1988), what we can partly confirm on the basis of our results. However, besides a generally higher incidence of abnormal morphotypes within the sapropel we also found peak abundances of those types shortly before local extinctions, indicating that they can also be the result of increased environmental stress as suggested by Caron et al. (1987). A general increase of the abundance of phentotypes that are more rare under optimal conditions can be interpreted in the lines of conservative bet-hedging, that has been shown to generally increase the mean fitness of a population in variable environments (Einum and Fleming, 2004). Thus we suggest here that abnormal morphotypes in O. universa are an adaptive response of that species toward less suitable or more variable environmental conditions. This explains both the general higher incidence of abnormal morphotypes within the early sapropel stages investigated here, during which the severe overturn in water mass circulation likely led to increased environmental variability before the system restabilized, as well as the peak abundances shortly before local extinctions, when some environmental factors must have been especially unfavorable for $O$. universa.

The deviation of the spiral growth pattern in G. scitula toward the terminal environmental stress is more difficult to explain. On the one hand, we were able to observe changes in the chamber-bychamber growth pattern. Under the assumption that the chamber 
size is proportional to the degree of cytoplasm growth, faster proportional chamber growth indicates that more cytoplasm was produced between the formation of two successive chambers. This could on the one hand be the result of disturbances in the timing of chamber formation, building new chambers less often, so that more cytoplasm has been produced since. This explanation would probably indicate a lack of nutrients, where the timing of chamber formation participates in a trade-off with cellular energy resources. On the other hand, chamber formation could occur on strictly regular time intervals, in which case larger chambers would indicate larger cytoplasm growth per time as result of higher nutrient availability.

At the same time, however, we observe a decrease in the intra-individual evenness of chamber growth, indicating either a reduction in the ability of the cell to control the exact size of the chamber produced, or a more irregular time-pattern of chamber formation. Conversely, the ability of the cell to maintain its logarithmic spiral growth pattern is retained. Interestingly, the observed increase in $I G V$ is itself subject to an increased inter-individual variability when the species approaches local extinction. This observation can be interpreted in at least two ways. (1) It is possible that the elevated level of environmental stress had not affected the entire interval of 60-70 yrs expected to be represented by the last sample before local extinction, and thus only the historically younger part of the community shows the described effect. We could not find a significant deviation from unimodality in the $I G V$ data of $G$. scitula from the last sample before extinction $(p=0.877)$, principally arguing against that hypothesis. (2) The increase in $I G V$ variability in G. scitula could also be interpreted as bet-hedging under high-stress environmental conditions. In this case, we would expect higher variability of $I G V$ on the community level as a result of higher phenotypic plasticity. This phenomenon would represent a case of diversified bet-hedging (Einum and Fleming, 2004), where the overall variability of the population is increased in order to allow the survival of at least some offspring. Einum and Fleming (2004) suggested that diversified bet-hedging can only be of advantage for the population if the environment is very unstable, and the population is practically at the brink of extinction. Interestingly enough, the local extinction in G. scitula occurs contemporaneously with the onset of Sapropel S5, which led to heavy changes in the Eastern Mediterranean vertical circulation system. Accordingly, since a marine water-mass circulation cannot be changed spontaneously, it is reasonable to assume that such heavily variable environments prevailed at that time, especially at greater depths where G. scitula dwells, that are dependent on the supply by surface waters to remain environmentally stable. Such an interpretation could also explain why $O$. universa as a surface dweller (where the environmental change mainly consisted of a gradual change in salinity) showed conservative bet-hedging with sapropel onset, and why G. scitula was able to reinvade the Eastern Mediterranean after the sapropel conditions had been established (Figure 3) and the deeper water column was also stable again.

In conclusion, we suggest that there are two types of FA realized in Foraminifera. Such a distinction seems to be necessary to accommodate our results, and is reasonable due to the fact that the concept of FA was originally developed for bilateral multicellular organisms and is not applicable to protists in this narrow form. FA s.lat. represents the overall shape of the foraminifer shell, such as the roundness of O. universa shells or the logarithmic spiral of shells of G. scitula. This type of FA is robust against environmental stress (although it seems to be influenced by other environmental parameters) and is thus not suitable as proxy for local extinctions.

FA s.str. is here defined as the ability of a foraminifer to constrain the chamber by chamber growth pattern of its shell, and includes the incidence of abnormal morphotypes in O. universa and $I G$ and $I G V$ in G. scitula. Many of the abnormal specimens of benthic Foraminifera described as the result of water pollution seem to be more extreme forms of this FA s.str. (Alve, 1991; Burone et al., 2006). This form of FA thus seems to be the result of bet-hedging occurring under high stress conditions, providing a versatile tool to predict extinctions (Leung et al., 2000; Sánchez-Chardi et al., 2013).

\section{PREDICTABILITY OF EXTINCTION FROM PHENOTYPE HISTORY}

We could observe both long-term and short-term reactions in shell morphology of planktonic Foraminifera and can thus verify our initial hypothesis. Long-term changes in trait state result in constant trait-states over thousands of years and are associated with prevailing environmental shifts inducing certain morphotypes, and can under circumstances lead to stabilizing selection, reducing the variance in shell morphology within the population. We can interpret this as a signal for stable, possibly favorable environmental conditions, under circumstances with reduced stress levels. Short-term changes occur relatively abrupt and prevail for only decades or few centuries, and are the result of environmental stress reactions of the population toward a relatively sudden environmental shift, often associated with unstable environments.

Disruptive selection, on the other hand, leads to an increase in variance within the community, and can be observed on both short-term and long-term scales in planktonic Foraminifera. We hypothesize that disruptive selection is the imprint of a stress reaction toward unfavorable environments. The observed disruption can be interpreted as the possible result of bet-hedging, a process that increases the mean fitness of the population (Philippi and Seger, 1989). Our analysis shows, that bet-hedging can sometimes not prevent extinction, but can otherwise lead to a measurable increase in variance of the population over considerable time intervals. While bet-hedging as a phenomenon prevails in unicellular organisms (Veening et al., 2008) and has been hypothesized to be one of the most fundamental survival strategies (Beaumont et al., 2009), it has not been shown to occur in planktonic Foraminifera yet, and has thus never been considered as an environmental proxy so far.

We thus contribute to other studies by showing that many of the selective patterns observed in phylogenetically more advanced organisms occur in protists. Some of these mechanisms (bethedging) leave a discernable imprint of a unique population trait composition (FA s.str.) that can be used to predict local extinctions. While the overall architecture of the shells is very robust against environmental perturbations, the incremental growth pattern of foraminiferal shells (representing FA s.str.) can be a valuable proxy for environmental stress levels, given that the stress 
levels were raised over decades (100s of generations) so that the proportion of affected individuals in the sample is large enough to be detected.

\section{ACKNOWLEDGMENTS}

We want to thank Richard Telford (University of Bergen) for critical comments on the results of our study. Norman MacLeod (Natural History Museum London) is acknowledged for helpful comments on an earlier version of this manuscript. Further acknowledgment goes to the other members of the Micropaleontology work group in Bremen and the Minigraduiertenkolleg in Tübingen, whose contributions cannot be listed individually here. Manuel F. G. Weinkauf was supported by the LGFG Baden-Württemberg and the Johanna M. Resig Fellowship of the Cushman Foundation. Tobias Moller received funding from the German Research Foundation DFGgrant SCHU1605/3-1.

\section{SUPPLEMENTARY MATERIAL}

The Supplementary Material for this article can be found online at: http://www.frontiersin.org/journal/10.3389/fevo.2014.00064/ abstract

All morphometric raw data associated with this work are available on PANGAEA (doi: 10.1594/PANGAEA.832132).

\section{REFERENCES}

Alve, E. (1991). Benthic foraminifera in sediment cores reflecting heavy metal pollution in Sørfjord, western Norway. J. Foraminiferal Res. 21, 1-19. doi: 10.2113/gsjfr.21.1.1

André, A., Weiner, A., Quillévéré, F., Aurahs, R., Morard, R., Douady, C. J., et al. (2013). The cryptic and the apparent reversed: lack of genetic differentiation within the morphologically diverse plexus of the planktonic foraminifer Globigerinoides sacculifer. Paleobiology 39, 21-39. doi: 10.1666/0094-837339.1 .21

Aurahs, R., Treis, Y., Darling, K. F., and Kučera, M. (2011). A revised taxonomic and phylogenetic concept for the planktonic foraminifer species Globigerinoides ruber based on molecular and morphometric evidence. Mar. Micropaleontol. 79, 1-14. doi: 10.1016/j.marmicro.2010.12.001

Beasley, D. A. E., Bonisoli-Alquati, A., and Mousseau, T. A. (2013). The use of fluctuating asymmetry as a measure of environmentally induced developmental instability: a meta-analysis. Ecol. Indic. 30, 218-226. doi: 10.1016/j.ecolind.2013.02.024

Beaumont, H. J. E., Gallie, J., Kost, C., Ferguson, G. C., and Rainey, P. B. (2009). Experimental evolution of bet hedging. Nature 462, 90-93. doi: 10.1038 /nature08504

Bé, A. W. H., Hemleben, C., Anderson, O. R., and Spindler, M. (1979). Chamber formation in planktonic foraminifera. Micropaleontology 25, 294-307. doi: $10.2307 / 1485304$

Bull, J. J. (1987). Evolution of phenotypic variance. Evol. Int. J. Org. Evol. 41, 303-315. doi: 10.2307/2409140

Burone, L., Venturini, N., Sprechmann, P., Valente, P., and Muniz, P. (2006). Foraminiferal responses to polluted sediments in the Montevideo coastal zone, Uruguay. Mar. Pollut. Bull. 52, 61-73. doi: 10.1016/j.marpolbul.2005.08.007

Cane, T., Rohling, E. J., Kemp, A. E. S., Cooke, S., and Pearce, R. B. (2002). High-resolution stratigraphic framework for Mediterranean Sapropel S5: defining temporal relationships between records of Eemian climate variability. Palaeogeogr. Palaeoclimatol. Palaeoecol. 183, 87-101. doi: 10.1016/S00310182(01)00461-8

Caron, D. A., Faber, J. W. F., and Bé, A. W. H. (1987). Growth of the spinose planktonic foraminifer Orbulina universa in laboratory culture and the effect of temperature on life processes. J. Mar. Biol. Assoc. U.K. 67, 343-358. doi: $10.1017 /$ S0025315400026655

Davison, A. C., and Hinkley, D. V. (1997). Bootstrap Methods and their Applications. Cambridge: Cambridge University Press. doi: 10.1017/CBO9780511802843
Debat, V., Milton, C. C., Rutherford, S., Klingenberg, C. P., and Hoffmann, A. A. (2006). Hsp90 and the quantitative variation of wing shape in Drosophila melanogaster. Evol. Int. J. Org. Evol. 60, 2529-2538. doi: 10.1554/06-045.1

Delord, J. (2007). The nature of extinction. Stud. Hist. Philos. Sci. 38, 656-667. doi: 10.1016/j.shpsc.2007.06.004

De Vargas, C., Norris, R. D., Zaninetti, L., Gibb, S. W., and Pawlowski, J. (1999). Molecular evidence of cryptic speciation in planktonic foraminifers and their relation to oceanic provinces. Proc. Natl. Acad. Sci. U.S.A. 96, 2864-2868. doi: 10.1073/pnas.96.6.2864

Dixon, P. M. (2002). “Bootstrap resampling," in Encyclopedia of Environmetrics, eds A. H. El-Shaarawi and W. W. Piegorsch (Chichester: John Wiley \& Sons, Ltd.), 212-220.

Doebeli, M. (1996). A quantitative genetic competition model for sympatric speciation. J. Evol. Biol. 9, 893-909. doi: 10.1046/j.1420-9101.1996.9060893.x

Drake, J. M., and Griffen, B. D. (2010). Early warning signals of extinction in deteriorating environments. Nature 467, 456-459. doi: 10.1038/nature09389

Einum, S., and Fleming, I. A. (1999). Maternal effects of egg size in brown trout (Salmo trutta): norms of reaction to environmental quality. Proc. Biol. Sci. 266, 2095-2100. doi: 10.1098/rspb.1999.0893

Einum, S., and Fleming, I. A. (2004). Environmental unpredictability and offspring size: conservative versus diversified bet-hedging. Evol. Ecol. Res. 6, 443-455.

Furlow, F. B., Armijo-Prewitt, T., Gangestad, S. W., and Thornhill, R. (1997). Fluctuating asymmetry and psychometric intelligence. Proc. Biol. Sci. 264, 823-829. doi: 10.1098/rspb.1997.0115

Grafen, A. (1999). Formal Darwinism, the individual-as-maximizing-agent analogy and bet-hedging. Proc. Biol. Sci. 266, 799-803. doi: 10.1098/rspb.1999.0708

Grubbs, F. E. (1969). Procedures for detecting outlying observations in samples. Technometrics 11, 1-21. doi: 10.1080/00401706.1969.10490657

Haenel, P. (1987). Intérêt paléoocéanographique d'Orbulina universa d'Orbigny (foraminifère). Oceanol. Acta 10, 15-25.

Hartigan, J. A., and Hartigan, P. M. (1985). The dip test of unimodality. Ann. Stat. 13, 70-84. doi: 10.1214/aos/1176346577

Hemleben, C., Becker, T., Bellas, S., Benningsen, G., Casford, J., Cagatay, N., et al. (2003). Ostatlantik-Mittelmeer-Schwarzes Meer Part 3: Cruise No. 51, Leg 3. Hamburg: Leitstelle METEOR.

Hendrickx, F., Maelfait, J. P., and Lens, L. (2003). Relationship between fluctuating asymmetry and fitness within and between stressed and unstressed populations of the wolf spider Pirata piraticus. J. Evol. Biol. 16, 1270-1279. doi: 10.1046/j.1420-9101.2003.00633.x

Heslop, D., De Schepper, S., and Proske, U. (2011). Diagnosing the uncertainty of taxa relative abundances derived from count data. Mar. Micropaleontol. 79, 114-120. doi: 10.1016/j.marmicro.2011.01.007

Kučera, M. (2007). "Planktonic Foraminifera as tracers of past oceanic environments," in Proxies in Late Cenozoic Paleoceanography, eds C. HillaireMarcel, A. De Vernal, and H. Chamley (Amsterdam: Elsevier), 213-262. doi: 10.1016/S1572-5480(07)01011-1

Legendre, P., and Legendre, L. (2012). Numerical Ecology. Amsterdam; Oxford: Elsevier.

Lens, L., Van Dongen, S., Kark, S., and Matthysen, E. (2002). Fluctuating asymmetry as an indicator of fitness: can we bridge the gap between studies? Biol. Rev. Camb. Philos. Soc. 77, 27-38. doi: 10.1017/S1464793101005796

Leung, B., Forbes, M. R., and Houle, D. (2000). Fluctuating asymmetry as a bioindicator of stress: comparing efficacy of analyses involving multiple traits. Am. Nat. 155, 101-115. doi: 10.1086/303298

Ludwig, D. (1999). Is it meaningful to estimate a probability of extinction? Ecology 80, 298-310. doi: 10.1890/0012-9658(1999)080[0298:IIMTEA]2.0.CO;2

Malmgren, B. A., and Kennett, J. P. (1976). Biometric analysis of phenotypic variation in recent Globigerina bulloides d'Orbigny in the southern Indian Ocean. Mar. Micropaleontol. 1, 3-25. doi: 10.1016/0377-8398(76)90003-7

Mann, H. B., and Whitney, D. R. (1947). On a test of whether one of two random variables is stochastically larger than the other. Ann. Math. Stat. 18, 50-60. doi: 10.1214/aoms/1177730491

Marino, G., Rohling, E. J., Rijpstra, W. I. C., Sangiorgi, F., Schouten, S., and Damsté, J. S. S. (2007). Aegean Sea as driver of hydrographic and ecological changes in the Eastern Mediterranean. Geology 35, 675-678. doi: 10.1130/ G23831A.1

Mary, Y., and Knappertsbusch, M. W. (2013). Morphological variability of menardiform globorotalids in the Atlantic Ocean during Mid-Pliocene. Mar. Micropaleontol. 101, 180-193. doi: 10.1016/j.marmicro.2012.12.001 
Moller, T. (2012). Formation and Palaeoclimatic interpretation of a Continuously Laminated Sapropel S5: A Window to the Climate Variability During the Eemian Interglacial in the Eastern Mediterranean. Ph.D. thesis, Eberhard-Karls Universität Tübingen, Tübingen.

Moller, T., Schulz, H., Hamann, Y., Dellwig, O., and Kučera, M. (2012). Sedimentology and geochemistry of an exceptionally preserved last interglacial Sapropel S5 in the Levantine Basin (Mediterranean Sea). Mar. Geol. 291-294, 34-48. doi: 10.1016/j.margeo.2011.10.011

Moritz, C., and Agudo, R. (2013). The future of species under climate change: resilience or decline? Science 341, 504-508. doi: 10.1126/science. 1237190

Ortiz, J. D., Mix, A. C., and Collier, R. W. (1995). Environmental control of living symbiotic and asymbiotic Foraminifera of the California Current. Paleoceanography 10, 987-1009. doi: 10.1029/95PA02088

Pélabon, C., Hansen, T. F., Carter, A. J. R., and Houle, D. (2010). Evolution of variation and variability under fluctuating, stabilizing, and disruptive selection. Evol. Int. J. Org. Evol. 64, 1912-1925. doi: 10.1111/j.1558-5646.2010.00979.x

Philippi, T., and Seger, J. (1989). Hedging one's evolutionary bets, revisited. Trends Ecol. Evol. 4, 41-44. doi: 10.1016/0169-5347(89)90138-9

Pujol, C., and Vergnaud Grazzini, C. (1995). Distribution patterns of live planktic foraminifers as related to regional hydrography and productive systems of the Mediterranean Sea. Mar. Micropaleontol. 25, 187-217. doi: 10.1016/03778398(95)00002-I

R Development Core Team. (2013). R: a Language and Environment for Statistical Computing. Vienna: R Foundation for Statistical Computing.

Robbins, L. L. (1988). Environmental significance of morphologic variability in open-ocean versus ocean-margin assemblages of Orbulina universa. J. Foraminiferal Res. 18, 326-333. doi: 10.2113/gsjfr.18.4.326

Rohling, E., Abu-Zied, R., Casford, J., Hayes, A., and Hoogakker, B. (2009). "The marine environment: present and past," in The Physical Geography of the Mediterranean, ed J. Woodward (New York, NY: Oxford University Press), 33-67.

Rohling, E. J. (1994). Review and new aspects concerning the formation of Eastern Mediterranean sapropels. Mar. Geol. 122, 1-28. doi: 10.1016/00253227(94)90202-X

Rohling, E. J., Sprovieri, M., Cane, T., Casford, J. S. L., Cooke, S., Bouloubassi, I., et al. (2004). Reconstructing past planktic foraminiferal habitats using stable isotope data: a case history for Mediterranean Sapropel S5. Mar. Micropaleontol. 50, 89-123. doi: 10.1016/S0377-8398(03)00068-9

Rossignol-Strick, M., Nesteroff, W., Olive, P., and Vergnaud Grazzini, C. (1982). After the deluge: mediterranean stagnation and sapropel formation. Nature 295, 105-110. doi: 10.1038/295105a0

Rueffler, C., Van Dooren, T. J. M., Leimar, O., and Abrams, P. A. (2006). Disruptive selection and then what? Trends Ecol. Evol. 21, 238-245. doi: 10.1016/j.tree.2006.03.003

Sánchez-Chardi, A., García-Pando, M., and López-Fuster, M. J. (2013). Chronic exposure to environmental stressors induces fluctuating asymmetry in shrews inhabiting protected Mediterranean sites. Chemosphere 93, 916-923. doi: 10.1016/j.chemosphere.2013.05.056

Schiebel, R., Waniek, J., Zeltner, A., and Alves, M. (2002). Impact of the Azores front on the distribution of planktic foraminifers, shelled gastropods, and coccolithophorids. Deep Sea Res. II 49, 4035-4050. doi: 10.1016/S09670645(02)00141-8

Schmidt, D. N., Renaud, S., Bollmann, J., Schiebel, R., and Thierstein, H. R. (2004). Size distribution of Holocene planktic foraminifer assemblages: biogeography, ecology and adaptation. Mar. Micropaleontol. 50, 319-338. doi: 10.1016/S03778398(03)00098-7
Shapiro, S. S., and Wilk, M. B. (1965). An analysis of variance test for normality (complete samples). Biometrika 52, 591-611. doi: 10.1093/biomet/52.3-4.591

Sheskin, D. J. (2011). Handbook of Parametric and Nonparametric Statistical Procedures. Boca Raton; New York: Chapman \& Hall/CRC Press.

Slatkin, M. (1974). Hedging one's evolutionary bets. Nature 250, 704-705. doi: $10.1038 / 250704 \mathrm{~b} 0$

Spero, H. J. (1988). Ultrastructural examination of chamber morphogenesis and biomineralization in the planktonic foraminifer Orbulina universa. Mar. Biol. 99, 9-20. doi: 10.1007/BF00644972

Spero, H. J., Lerche, I., and Williams, D. F. (1991). Opening the carbon isotope "Vital Effect" black box, 2, quantitative model for interpreting foraminiferal carbon isotope data. Paleoceanography 6, 639-655. doi: 10.1029/91PA02022

Struck, U., Emeis, K.-C., Voß, M., Krom, M. D., and Rau, G. H. (2001). Biological productivity during Sapropel S5 formation in the Eastern Mediterranean Sea: evidence from stable isotopes of nitrogen and carbon. Geochim. Cosmochim. Acta 65, 3249-3266. doi: 10.1016/S0016-7037(01)00668-8

Tabachnick, B. G., and Fidell, L. S. (1996). Using Multivariate Statistics. New York, NY: Harper Collins.

Tabor, J. (2010). Investigating the investigative task: testing for skewness-an investigation of different test statistics and their power to detect skewness. J. Stat. Educ. 18, 1-13. http://www.amstat.org/publications/jse/v18n2/tabor.pdf

Van Der Meer, M. T. J., Baas, M., Rijpstra, W. I. C., Marino, G., Rohling, E. J., Damsté, J. S. S., et al. (2007). Hydrogen isotopic compositions of longchain alkenones record freshwater flooding of the Eastern Mediterranean at the onset of sapropel deposition. Earth Planet. Sci. Lett. 262, 594-600. doi: 10.1016/j.epsl.2007.08.014

Van Valen, L. (1965). Morphological variation and width of ecological niche. Am. Nat. 99, 377-390. doi: 10.1086/282379

Veening, J.-W., Smits, W. K., and Kuipers, O. P. (2008). Bistability, epigenetics, and bet-hedging in bacteria. Annu. Rev. Microbiol. 62, 193-210. doi: 10.1146/annurev.micro.62.081307.163002

Weinkauf, M. F. G., Moller, T., Koch, M. C., and Kučera, M. (2013). Calcification intensity in planktonic foraminifera reflects ambient conditions irrespective of environmental stress. Biogeosciences 10, 6639-6655. doi: 10.5194/bg-106639-2013

Williams, D. F., Thunell, R. C., and Kennett, J. P. (1978). Periodic freshwater flooding and stagnation of the Eastern Mediterranean Sea during the late Quaternary. Science 201, 252-254. doi: 10.1126/science.201.4352.252

Conflict of Interest Statement: The authors declare that the research was conducted in the absence of any commercial or financial relationships that could be construed as a potential conflict of interest.

Received: 12 August 2014; accepted: 24 September 2014; published online: 14 October 2014.

Citation: Weinkauf MFG, Moller T, Koch MC and Kučera M (2014) Disruptive selection and bet-hedging in planktonic Foraminifera: shell morphology as predictor of extinctions. Front. Ecol. Evol. 2:64. doi: 10.3389/fevo.2014.00064

This article was submitted to Paleoecology, a section of the journal Frontiers in Ecology and Evolution.

Copyright (C) 2014 Weinkauf, Moller, Koch and Kučera. This is an open-access article distributed under the terms of the Creative Commons Attribution License (CC BY). The use, distribution or reproduction in other forums is permitted, provided the original author(s) or licensor are credited and that the original publication in this journal is cited, in accordance with accepted academic practice. No use, distribution or reproduction is permitted which does not comply with these terms. 